\title{
Src kinases in chondrosarcoma chemoresistance and migration: dasatinib sensitises to doxorubicin in TP53 mutant cells
}

\author{
J G van Oosterwijk ${ }^{1}$, M A J H van Ruler ${ }^{1}$, I H Briaire-de Bruijn ${ }^{1}$, B Herpers ${ }^{2}$, H Gelderblom ${ }^{3}$, B van de Water ${ }^{2}$ \\ and J V M G Bovée*,1 \\ ${ }^{1}$ Department of Pathology, Leiden University Medical Center, Albinusdreef 2, 2333 ZA Leiden, The Netherlands; ${ }^{2}$ Division of \\ Toxicology, Leiden/Amsterdam Centre for Drug Research, Einsteinweg 55, 2333 CC Leiden, The Netherlands and ${ }^{3}$ Department of \\ Clinical Oncology, Leiden University Medical Center, Albinusdreef 2, 2333 ZA Leiden, The Netherlands
}

Background: Chondrosarcomas are malignant cartilage-forming tumours of bone. Because of their resistance to conventional chemotherapy and radiotherapy, currently no treatment strategies exist for unresectable and metastatic chondrosarcoma. Previously, PI3K/AKT/GSK3 $\beta$ and Src kinase pathways were shown to be activated in chondrosarcoma cell lines. Our aim was to investigate the role of these kinases in chemoresistance and migration in chondrosarcoma in relation to TP53 mutation status.

Methods: We used five conventional and three dedifferentiated chondrosarcoma cell lines and investigated the effect of PI3K/AKT/GSK3 $\beta$ pathway inhibition (enzastaurin) and Src pathway inhibition (dasatinib) in chemoresistance using WST assay and live cell imaging with AnnexinV staining. Immunohistochemistry on tissue microarrays (TMAs) containing 157 cartilaginous tumours was performed for Src family members. Migration assays were performed with the RTCA xCelligence System.

Results: Src inhibition was found to overcome chemoresistance, to induce apoptosis and to inhibit migration. Cell lines with TP53 mutations responded better to combination therapy than wild-type cell lines $(P=0.002)$. Tissue microarray immunohistochemistry confirmed active Src (pSrc) signalling, with Fyn being most abundantly expressed (76.1\%).

Conclusion: These results strongly indicate Src family kinases, in particular Fyn, as a potential target for the treatment of inoperable and metastatic chondrosarcomas, and to sensitise for doxorubicin especially in the presence of TP53 mutations.

Chondrosarcoma is a malignant cartilage-forming neoplasm of bone and the second most common bone sarcoma in humans (Hogendoorn et al, 2013). Conventional chondrosarcoma does not respond to existing chemo- and radiotherapy modalities (Gelderblom et al, 2008). Metastasis formation eventually occurs in $71 \%$ of grade III chondrosarcoma cases, and with a 10 -year survival rate of $29 \%$, this poses a serious treatment problem (Evans et al, 1977).

Chemoresistance in chondrosarcoma has long been ascribed to poor vascularisation, hyaline extracellular matrix production and slowly dividing cells (Staals et al, 2006; David et al, 2011). Though this is true for low-grade chondrosarcomas, high-grade chondrosarcomas typically are composed of rapidly dividing cells with more myxoid matrix production (Gelderblom et al, 2008; Bovée et al, 2010). In the search for molecular targets, negative regulators of the apoptotic pathway, such as BCL-2 (Bovée et al, 2000; Hameetman et al, 2005; Rozeman et al, 2005; Soderstrom et al, 2010) and survivin (Lechler et al, 2011), were identified to be upregulated in chondrosarcoma, and shown to have a role in chemoresistance (Lechler et al, 2011; van Oosterwijk et al, 2012a).

Apart from defective apoptotic pathways, deregulated kinase pathways are of growing interest in the field of cancer and have been suggested to have a role in chondrosarcoma (Bovée et al, 2010). We have previously shown activating hyperphosphorylation 
of AKT, and Src family kinases and inactivating hyperphosphorylation of GSK $3 \beta$ using kinome profiling of chondrosarcoma cell lines and primary cultures (Schrage et al, 2009).

Both PI3K/AKT/GSK $3 \beta$ and Src signalling pathways are described in a variety of different cancer types as well as in progression to malignancy (Verbeek et al, 1996; Aligayer et al, 2002; Gelman, 2011; McNamara and Degterev, 2011) and can be activated by receptor tyrosine kinases (RTKs) (Goode et al, 1992; Wheeler et al, 2009; Saini et al, 2011). Activation of the Src pathway promotes cell survival, proliferation and migration, but can also activate the PI3K/AKT/GSK3 $\beta$ pathway through phosphorylation of $\mathrm{PI} 3 \mathrm{~K}$, thereby leading to increased AKT phosphorylation (Johnson et al, 2000). Activation of protein kinase $\mathrm{C}$ (PKC) by RTKs can also activate the PI3K/AKT pathway, either through phosphorylation of PI3K or through direct phosphorylation of AKT (Aeder et al, 2004; Kawakami et al, 2004; Figure 1A). Moreover, PKC and AKT can both phosphorylate GSK3 $\beta$ at Ser9 (Goode et al, 1992; Fang et al, 2002).

Because of the intricate interplay of PI3K/AKT/GSK3 $\beta$ and Src signalling pathways in cancer and the observation that both pathways are activated in chondrosarcoma, we hypothesised that the activation of these pathways in chondrosarcoma contributes to chemoresistance.

We therefore investigated the role of both pathways in cell proliferation and chemoresistance. Our data indicate that Src family kinases, Fyn in particular, have a role in chemoresistance and cell migration, and that TP53-mutated cells are especially sensitive to combination therapy with doxorubicin and the Src inhibitor dasatinib.

\section{MATERIALS AND METHODS}

Compounds. Doxorubicin and cisplatin were obtained from the in-house hospital pharmacy in a $0.9 \% \mathrm{NaCl}$ solution. Therapeutic concentrations of doxorubicin in patients are $5-50 \mu \mathrm{M}$ with an in vitro range of $1-10 \mu \mathrm{M}$, for cisplatin these are $3-13 \mu \mathrm{M}$ with an in vitro range of $1-50 \mu \mathrm{M}$ (Shrivastav et al, 1980). The PKC inhibitor enzastaurin (Faul et al, 2003; Eli Lilly, IN, USA) and the Src inhibitor dasatinib (Lombardo et al, 2004) (Bristol-Meyers Squibb, Princeton, NJ, USA) were dissolved in DMSO.

Cell culture. Chondrosarcoma cell lines (Table 1), as well as MCF-7 and HeLa cell lines were cultured in RPMI 1640 (Gibco, Invitrogen Life Technologies, Scotland, UK) supplemented with $1 \%$ L-glutamax, $1 \%$ penicillin-streptomycin $\left(100 \mathrm{U} \mathrm{ml}^{-1}\right)$ and $10 \%$ heat-inactivated fetal calf serum (Gibco, Invitrogen Life Technologies, Scotland, UK). Cells were grown at $37^{\circ} \mathrm{C}$ in a humidified incubator with $95 \%$ air and $5 \% \mathrm{CO}_{2}$. Cells were cultured until they started multiplying stably. Chondrogenic phenotype was confirmed using RT-PCR for collagen I, IIB, III and X, aggrecan and SOX9 (Cleton-Jansen et al, 2005). Identity of cell lines was confirmed using the Cell ID System after completion of experiments (Promega Benelux BV, Leiden, The Netherlands).

Cell viability assay. Chondrosarcoma cell lines were plated in 96-well plates for viability assessment $\left(2 \times 10^{4}-2 \times 10^{5}\right.$ cells per well depending on growth rate) and allowed to grow and adhere overnight after which the respective drugs were added in their corresponding concentrations. Combination assays were performed as described (van Oosterwijk et al, 2012b) with alternating treatments combining enzastaurin, dasatinib and/or doxorubicin. All experiments were performed in triplicate and at least three times. Graphs show data from one representative experiment. Error bars indicate the s.d.

Immunoblotting. Immunoblotting using AKT, pAKT, Fyn (Cell Signaling, Leiden, the Netherlands) and pSrc antibody
(pSrc pY418, Invitrogen Life Technologies, Bleiswijk, the Netherlands) to investigate the Src and PI3K/AKT signalling pathway and p53 (Do7, Dako, Heverlee, Belgium), MDM2 (IF2, Zymed, Bleiswijk, the Netherlands) and p21 (Santa Cruz, Heidelberg, Germany) was performed as previously described (Schrage et al, 2009), using $20 \mu \mathrm{g}$ of each sample.

Mutation analysis. To identify mutations in AKT1, direct sequencing was performed as described (Pansuriya et al, 2011), using DNA derived from 57 tumours, 8 cell lines and 1 primary culture (L3310) using forward primer 3'-TAGAGTGTGCGTGGC CTCTCA- $5^{\prime}$ and reverse primer $3^{\prime}$-CTGAATCCCGAGAGGCC AA $-5^{\prime}$ to screen for hotspot mutations in the AKT1-E17K pleckstrin homology domain.

Apoptosis assay and immunofluorescence. Apoptosis assay and immunofluorescence for caspase 3 and cytochrome C were performed as described (Puigvert et al, 2010; van Oosterwijk et al, 2012b). In short, 20000 chondrosarcoma cells were grown in black 96-well microclear plates (Greiner, Sigma-Aldrich, Zwijndrecht, the Netherlands) to perform a live cell apoptosis assay (Puigvert et al, 2010), with AnnexinV-Alexa633 conjugate using the BD Pathway 855 (Becton Dickinson, Breda, the Netherlands). Time series were quantified using in-housedeveloped macros for Image-Pro Plus (Media Cybernetics, Bethesda, MD, USA). Drugs were added 0,24 , and $48 \mathrm{~h}$ before imaging and Annexin V-Alexa633 conjugate was added immediately before imaging. For all treatments, a pan-caspase inhibitor, z-VAD-fmk (Bachem-Holding AG, Weil am Rhein, Germany), was added 30 min before drug addition and imaging to establish apoptosis specificity of the assay. Before imaging, live nuclei were stained with HOECHST-33342 at $100 \mathrm{ng} \mathrm{ml}^{-1}$. All experiments were performed in triplicate and at least three times. Error bars show s.d. from one representative experiment.

Migration assays. The RTCA xCelligence system (Roche Applied Sciences, Almere, the Netherlands), based on cell-electrode substract impedance detection technology, was used for migration assays. For migration assays, lower wells of the SIM plates (migration plates) were filled with growth medium (20\% fetal calf serum in RPMI). Cell lines were plated at a density of 80000 cells per well in the top wells in empty buffer (RPMI only) containing 0 , $0.2,0.4,0.6,0.8$ or $1.0 \mu \mathrm{M}$ dasatinib. SIM plates were loaded into the RTCA station in the cell culture incubator immediately after plating and cell index was acquired every $5 \mathrm{~min}$. Cell index as acquired by the software was set to $100 \%$ migration after flattening of the slope. Experiments were performed in triplicate.

Tissue microarray (TMA) construction and clinicopathological data. Tissue microarrays were constructed from formalin-fixed, paraffin-embedded tissue using standard procedures (Kononen et al, 1998) using a $2.0-\mathrm{mm}$ diameter punch-automated tissue arrayer (3DHistech Ltd, Budapest, Hungary). Each array contained three cores per tumour wherever possible including seven control tissues (skin, colon, tonsil, prostate, mamma carcinoma, spleen and liver). Using a tape-transfer system (Instrumedics, Hackensack, NJ, USA), $4-\mu$ m sections were transferred to glass slides. All specimens in this study were handled according to the ethical guidelines described in 'Code for Proper Secondary Use of Human Tissue in The Netherlands' of the Dutch Federation of Medical Scientific Societies. A total of 157 patients with cartilaginous tumours were selected from the archives of the Leiden University Medical Centre. Selected cases included 137 conventional chondrosarcomas (central chondrosarcoma, $n=92$; peripheral chondrosarcoma, $n=45$ ) and 20 benign cartilage tumours (osteochondroma, $n=9$; enchondroma, $n=11$ ). Only primary tumours were selected. Histology was reviewed by an experienced bone tumour pathologist (JVMGB). Clinicopathological data are shown in Table 2. Total follow-up was available for 136 of 157 patients, with 


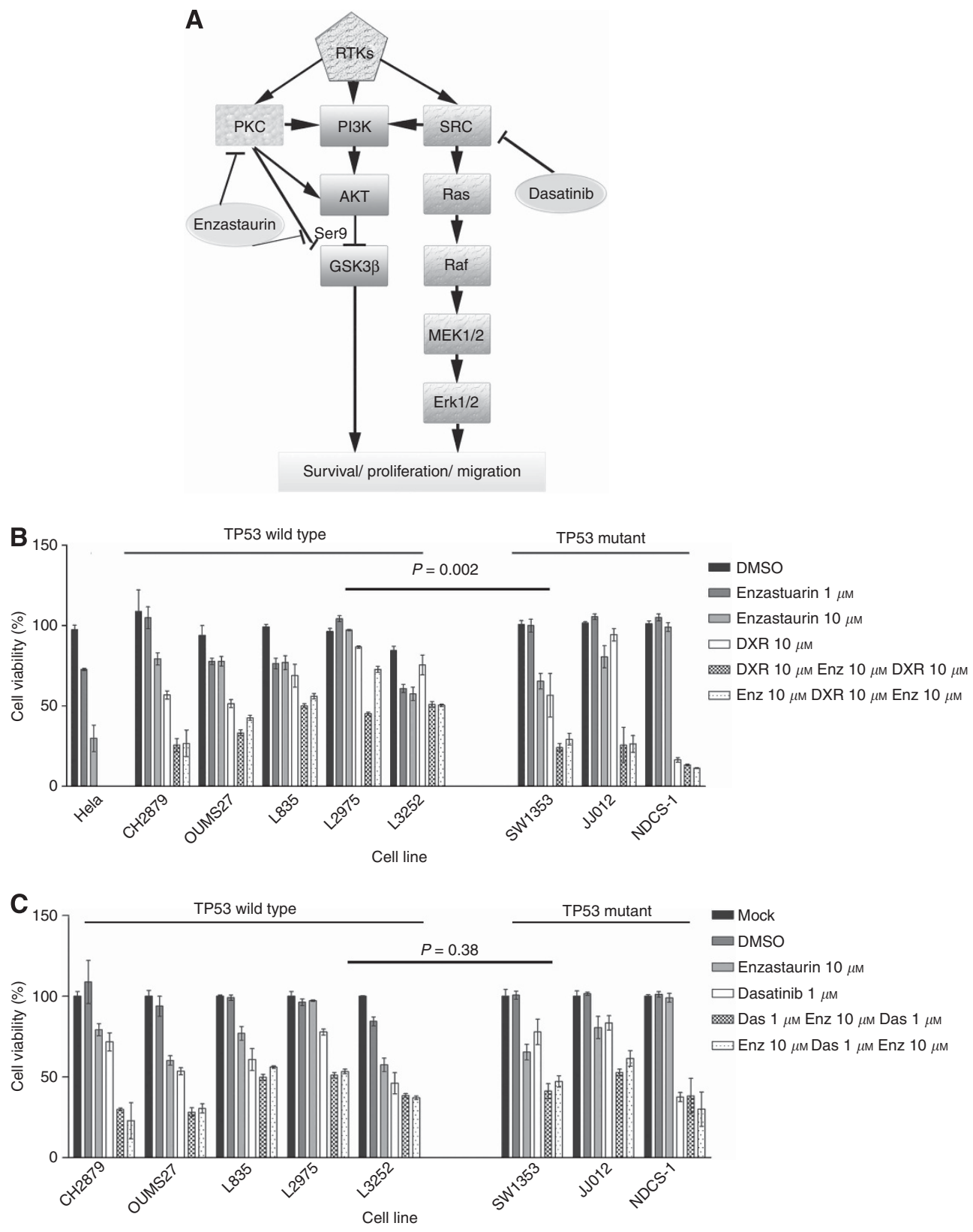

Figure 1. Chondrosarcoma cell lines are not sensitive to PKC inhibition. (A) Schematic representation of activation of PI3K and Src pathway by RTKs. Receptor tyrosine kinases can activate PKC, phosphatidylinositol 3-kinase (PI3K) and Src. PKC and Src can also activate the PI3K/AKT/ GSK3 $\beta$ pathway, promoting survival, proliferation and migration. The Src pathway activates the Ras/Raf pathway. Enzastaurin is a selective PKC inhibitor also reported to inhibitin activating phosphorylation of GSK3 $\beta$. Dasatinib is a Src inhibitor. Adapted from Fizazi (2007). (B) HeLa cell line showing $70 \%$ decrease in cell viability after treatment with enzastaurin. Chondrosarcoma cell lines poorly respond to enzastaurin alone, and an additive effect is observed when alternating $10 \mu \mathrm{m}$ doxorubicin (DXR) and $10 \mu \mathrm{m}$ enzastaurin (Enz) for $24 \mathrm{~h}$ each for $72 \mathrm{~h}$ in total. No difference is observed when order of administration is reversed. Significant difference between TP53 mutant and wild-type cell lines $(P=0.002)$. (C) Combination of enzastaurin with Src inhibitor dasatinib (Das) showing additive effect in chondrosarcoma cell lines. No significant difference is observed between TP53 mutant and wild-type cell lines $(P=0.38)$.

14 patients showing metastasis at completion of this study. Histological grading of chondrosarcoma was performed according to Evans et al (1977). Rare chondrosarcoma subtypes were excluded.

Immunohistochemistry. Immunohistochemistry was performed on the TMAs. Slides were incubated with antibodies against Src, Lck, Fyn, Yes and phosphorylated Src (pSrc, recognises active Src family members phosphorylated at Y419). Details of antibodies and procedures are provided in Supplementary Table 1.
Immunohistochemical reactions were performed according to standard laboratory methods (Bovée et al, 2000) and visualised using DAB + Substrate Chromogen System (Dako, Heverlee, Belgium). Tissue microarray slides were scanned using a high-resolution Mirax Desk Instrument (Zeiss, Mirax 3DHistech) and scored independently by two observers (JVMGB and JGvO) and discrepancies were discussed. Staining intensity $(0=$ absent, $1=$ weak, $2=$ moderate, $3=$ strong) and extent of the staining $(0=0 \%, 1=1-24 \%, 2=25-49 \%, 3=50-74 \%$ and $4=75-100 \%)$ were assessed. Staining was considered high (score $\geqslant 4$ ) or low 
Table 1. Chondrosarcoma cell lines

\begin{tabular}{|c|c|c|c|c|c|c|c|c|c|}
\hline Cell Line & Tumour type & Grade & Gender & Age & Passage & $\mathrm{TP}^{2} 3^{\mathrm{a}}$ & $\mathrm{IDH}^{\mathrm{b}}$ & $\mathrm{IDH} 2^{\mathrm{b}}$ & Reference \\
\hline SW1353 & Solitary central & II & $\mathrm{F}$ & 72 & 21 & V203L & wt & R172S & Commercial (ATCC) \\
\hline OUMS27 & Solitary central & III & $\mathrm{M}$ & 65 & 27 & wt & wt & wt & Kunisada et al (1998) \\
\hline $\mathrm{CH} 2879$ & Solitary central & III & $\mathrm{F}$ & 35 & $>80$ & wt & wt & wt & Gil-Benso et al (2003) \\
\hline JJ012 & Solitary central & II & M & 39 & 9 & G199V & R132G & wt & Scully et al (2000) \\
\hline L835 & Solitary central & III & $M$ & 55 & 50 & wt & R132C & wt & van Oosterwijk et al (2012a) \\
\hline L2975 & Dedifferentiated & & $M$ & 57 & 60 & wt & R172W & wt & van Oosterwijk et al (2012a) \\
\hline NDCS1 & Dedifferentiated & & $M$ & 38 & 60 & C242S & wt & wt & Kudo et al (2007) \\
\hline L3252 & Dedifferentiated & & $\mathrm{F}$ & 52 & 30 & wt & wt & wt & van Oosterwijk et al (2012a) \\
\hline
\end{tabular}

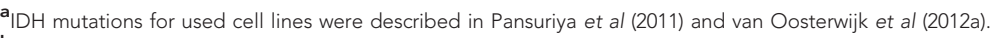

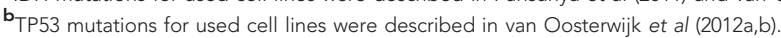

\begin{tabular}{|c|c|c|}
\hline & $\begin{array}{c}\text { Peripheral } \\
(n=45)\end{array}$ & $\begin{array}{l}\text { Central } \\
(n=92)\end{array}$ \\
\hline Male vs female & 27 vs 18 & 39 vs 53 \\
\hline Median age at diagnosis (years) & $37(14-82)$ & $50(20-84)$ \\
\hline \multicolumn{3}{|l|}{ Histology } \\
\hline $\begin{array}{l}\text { Grade I } \\
\text { Grade II } \\
\text { Grade III }\end{array}$ & $\begin{array}{r}31 \\
11 \\
3\end{array}$ & $\begin{array}{l}42 \\
36 \\
14\end{array}$ \\
\hline Metastasis & $4 / 45$ & $10 / 92$ \\
\hline Median follow-up (months) & $121(15-299)$ & $103(7-292)$ \\
\hline
\end{tabular}

$($ score $<4)$. As external positive and negative control for all the antibodies, specimens of normal tonsil were used. Cores with a negative internal control or loss of tissue were excluded from the analysis.

Statistical analysis. Survival was evaluated by Kaplan-Meier analysis and the log-rank test. Values of $P \leqslant 0.05$ were considered statistically significant. Variables that achieved significance $(P \leqslant 0.05)$ were entered subsequently into a multivariate analysis using the Cox regression model. Cox regression analysis was carried out with clinical outcome (overall survival) as the independent variable. Correlation between expression and grade and individual stainings were evaluated using Pearson chi-squared test for independent variables. Values of $P \leqslant 0.05$ for asymptomatic two-sided testing were considered significant. The data were analysed using SPSS version 17.0 software (Chicago, IL, USA).

For combination assays, the combination index according to the method of Chou and Talalay (1984) was calculated. A combination index (CI) of below 1 indicates synergy, and CI of above 1 indicates additive effect. Correlation between combination indices was evaluated using independent two-sided $t$-test using GraphPad Prism 5 software (La Jolla, CA, USA). Values of $P \leqslant 0.05$ were considered significant.

\section{RESULTS}

$\mathrm{PI} 3 \mathrm{~K} / \mathrm{AKT} / \mathrm{GSK} 3 \boldsymbol{\beta}$ pathway is not involved in chemoresistance of chondrosarcoma cell lines. To investigate the PI3K/AKT/ GSK3 $\beta$ pathway, chondrosarcoma cells were treated with $1 \mu \mathrm{m}$ and $10 \mu \mathrm{M}$ enzastaurin (Faul et al, 2003), a PKC $\beta$ inhibitor shown to inhibit AKT signalling and GSK3 $\beta$ phosphorylation (Graff et al, 2005). Whereas the cervical cancer cell line HeLa shows $70 \%$ reduction in cell viability after treatment with $10 \mu \mathrm{m}$ enzastaurin (Figure 1B), chondrosarcoma cell lines were less sensitive to enzastaurin treatment. Two chondrosarcoma cell lines showed complete resistance (NDCS-1 and L2975), whereas in the two most responsive cell lines (SW1353 and L3252) a maximum reduction in cell viability of $\sim 40 \%$ was achieved (Figure $1 \mathrm{~B}$ ). As the PI3K/AKT/ GSK3 $\beta$ pathway is involved in cell survival, we set out to examine its role in chemoresistance. Enzastaurin was combined with doxorubicin over the course of $72 \mathrm{~h}$, alternating treatments every $24 \mathrm{~h}$, as we previously showed that drug administration on separate days was most effective (van Oosterwijk et al, 2012b). While there was no difference in response between IDH-mutated and IDH wild-type cell lines, cell lines with TP53 mutations responded better to combination treatment than TP53 wild-type cell lines $(P=0.002$; Figure 1B). However, a lack of synergy between the two drugs was observed (combination indices $>2$ ), as reduction in cell viability was attributed to the effect of doxorubicin alone (NDCS1) or the additive effect of enzastaurin and doxorubicin. Activation of AKT1 can be through mutations in the pleckstrin homology domain, found mostly in solid tumours (Mahajan and Mahajan, 2012), leading to activated downstream signalling and decreased sensitivity to kinase inhibitors (Carpten et al, 2007). Hotspot mutations in the pleckstrin homology domain of AKT1 were absent in the primary chondrosarcoma tumour tissues or cell lines.

Inhibition of Src family kinases with dasatinib does not potentiate the effect of enzastaurin in chondrosarcoma cell lines. To exclude active Src signalling causing the limited response we observed to enzastaurin, we combined enzastaurin with the Src inhibitor dasatinib. In five cell lines (CH2879, OUMS27, SW1353, NDCS-1 and L3252), cell viability after combination treatment dropped below 50\% (Figure 1C). However, the reduction in cell viability could not be ascribed to a synergistic effect in any of the cell lines. Rather it was found to be due to the effect of dasatinib (L835, NDCS-1 and L3252) or the additive effect of dasatinib and enzastaurin (combination indices $>2$, Figure 1C). TP53 mutation status was not correlated to response $(P=0.38$, Figure $1 \mathrm{C})$. Interestingly, treatment with $1 \mu \mathrm{M}$ dasatinib for $24 \mathrm{~h}$ was found to decrease phosphorylation of AKT in OUMS27, L835, L3252 and NDCS-1 cell lines (Figure 2A).

Src signalling contributes to chemoresistance of chondrosarcoma cells. We have previously shown Src signalling to be involved in chondrosarcoma cell proliferation (Schrage et al, 2009). Immunoblotting confirmed the presence of phosphorylated Src (Y418) in the chondrosarcoma cell lines, with lowest expression in 

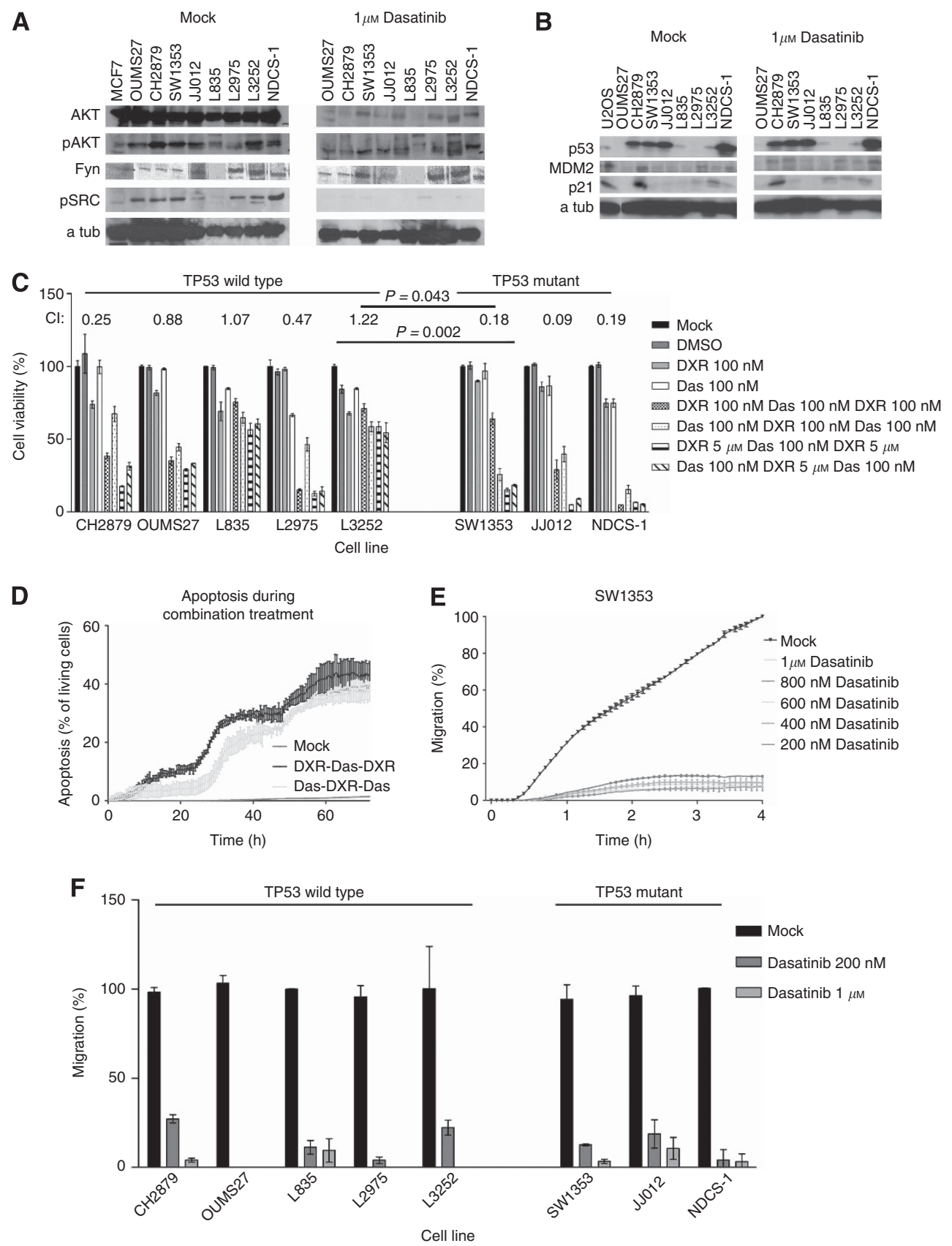

Figure 2. The Src pathway is involved in chondrosarcoma chemoresistance. (A) Immunoblotting showing AKT, pAKT, Fyn, pSrc and loading control $\alpha$-tubulin (a tub) for untreated chondrosarcoma cell lines and after 24-h $1 \mu \mathrm{m}$ dasatinib. MCF-7: breast cancer cell line, shown as positive control. Presence of all kinases in all cell lines phophorylated Src in all cell lines, although levels are very low in L835. After 24-h $1 \mu \mathrm{M}$ dasatinib treatment, levels of pSrc (at Y418) are decreased in all cell lines, and of pAKT in OUMS27, L835, L3252, JJ012 and NDCS-1.

(B) Immunoblotting showing p53, MDM2 and p21 in untreated chondrosarcoma cell lines (Mock) and after 24-h $1 \mu \mathrm{M}$ dasatinib. U2OS (osteosarcoma) cell line is shown as positive control. MDM2 expression is low in all cell lines. TP53 wild-type cell lines are negative for p53 protein expression, with low p21 protein expression, except for $\mathrm{CH} 2879$. TP53 mutant cell lines show high TP53 protein expression with low p21 protein expression. No change in protein levels is observed after 24-h $1 \mu \mathrm{m}$ dasatinib treatment. (C) Combination of dasatinib (Das) with doxorubicin (DXR) leads to synergistic loss of cell viability at concentrations, which are ineffective on their own in most cell lines. Combination treatment was more effective in TP53 mutant cell lines than in TP53 wild-type cell lines ( $P=0.002$ for cell viability, $P=0.043$ for combination indices). (D) Apoptosis assay in JJ012 cell line alternating $1 \mu \mathrm{M}$ dasatinib (Das) and $1 \mu \mathrm{M}$ doxorubicin (DXR) demonstrates the occurrence of apoptosis during combination. Apoptosis is calculated as percentage of AnnexinV-Alexxa633-stained cells per total number of HOECHST-stained cells. (D and E) Dasatinib successfully inhibits migration in chondrosarcoma cell lines in concentrations as low as $200 \mathrm{nM}$. (E) SW1353 cell line shown as representative over the course of $4 \mathrm{~h}$; (F) bar chart showing migration for all cell lines.

L835 cells, and $24 \mathrm{~h}$ with $1 \mu \mathrm{m}$ dasatinib resulted in decreased pSrc levels (Figure 2A). To examine the role of Src signalling in chemoresistance, dasatinib was combined with doxorubicin. A synergistic effect was observed in cell lines CH2879, OUMS27,
SW1353, JJ012, NDCS-1 and L2975 (combination indices ranging from 0.09 to 0.88 ; Figure $2 \mathrm{C}$ ), and the order of drug administration did not influence efficacy. Interestingly, a significant difference between both the cell viability $(P=0.002)$ and the combination 
indices $(P=0.043)$ was observed between cell lines with and without TP53 mutations, and both cell lines that were resistant to combination treatment (L835 and L3252) were wild type for TP53 mutations. We continued to investigate p53 accumulation as well as MDM2 and p21 expression in cells treated with and without treatment with dasatinib (Figure 2B). As expected, high p53 protein expression with low to absent p21was seen in the three TP53 mutant cell lines. All TP53 wild-type cell lines demonstrated low p53 and p21 protein expression with the exception of $\mathrm{CH} 2879$, demonstrating high levels of p53 and p21. Protein levels were not affected by dasatinib treatment. All cell lines showed low MDM2 protein expression.

No correlation with IDH mutations was found.

Src inhibition combined with doxorubicin induces apoptosis. Using annexinV-binding live cell imaging, we confirmed our previous findings (Schrage et al, 2009) that dasatinib monotreatment does not induce apoptosis (Figure 2D, first $24 \mathrm{~h}$ ). However, when combined with doxorubicin, up to $50 \%$ of cells had entered apoptosis after completion of the third cycle of combination treatment (JJ012 cell line shown as a representative cell line, Figure 2D). Because of the effect of doxorubicin during the first
$24 \mathrm{~h}, 10 \%$ more cells had entered apoptosis during combination treatment starting doxorubicin, than during combination treatment starting with dasatinib. Apoptosis could be inhibited using the pan-caspase inhibitor $\mathrm{z}$-VAD-fmk (results not shown).

Dasatinib inhibits migration of chondrosarcoma cell lines. As Src family members also have a role in motility and adhesion (Saito et al, 2010), we continued to investigate the migratory capacity of the chondrosarcoma cell lines. Using a transwell system, all chondrosarcoma cell lines showed migratory properties, and started migrating $\sim 30$ min after plating, except for JJ012 cells, which started migrating only $4 \mathrm{~h}$ after plating (results not shown). In the presence of dasatinib, however, a complete inhibition of cell migration was achieved for all cell lines at concentrations as low as $200 \mathrm{~nm}$ (Figure 2E and F). No difference between cell lines harbouring TP53 mutations and wild-type cell lines was observed.

Fyn is the most important Src family member in chondrosarcoma tissues. To identify the most important Src family member in chondrosarcoma, we evaluated the expression of the 4 family members Src, Yes, Fyn and Lck, as well as pSrc in primary tumour samples. Active Src signalling as evidenced by positive staining for pSrc was found in $88-100 \%$ of the tumours (Table 3,

\begin{tabular}{|c|c|c|c|c|c|c|c|c|}
\hline \multicolumn{6}{|c|}{ Peripheral chondrosarcoma } & \multicolumn{3}{|c|}{ Central chondrosarcoma } \\
\hline & Osteochondroma & Grade I & Grade II & Grade III & Enchondroma & Grade I & Grade II & Grade III \\
\hline pSrc & $3 / 3(100 \%)$ & $12 / 13(92 \%)$ & $6 / 6(100 \%)$ & $3 / 3(100 \%)$ & $4 / 5(80 \%)$ & $21 / 24(88 \%)$ & $21 / 22(96 \%)$ & $10 / 10(100 \%)$ \\
\hline Src & $1 / 7(14 \%)$ & $7 / 17$ (41\%) & $8 / 8(100 \%)$ & $2 / 3(67 \%)$ & $4 / 7(57 \%)$ & $12 / 31(39 \%)$ & $12 / 31(39 \%)$ & $7 / 13(54 \%)$ \\
\hline Yes & $0 / 7(0 \%)$ & $3 / 23(13 \%)$ & $0 / 10(0 \%)$ & $0 / 3(0 \%)$ & $0 / 7(0 \%)$ & $0 / 36(0 \%)$ & $3 / 30(10 \%)$ & $0 / 14(0 \%)$ \\
\hline Fyn & $7 / 8(88 \%)$ & $16 / 20(80 \%)$ & $9 / 10(90 \%)$ & $3 / 3(100 \%)$ & $5 / 5(100 \%)$ & $17 / 35(49 \%)$ & $31 / 35(89 \%)$ & $13 / 14(93 \%)$ \\
\hline Lck & $0 / 3(0 \%)$ & $1 / 23(4 \%)$ & $2 / 10(20 \%)$ & $0 / 3(0 \%)$ & $0 / 7(0 \%)$ & $1 / 38(3 \%)$ & $0 / 33(0 \%)$ & $2 / 13(15 \%)$ \\
\hline
\end{tabular}

A

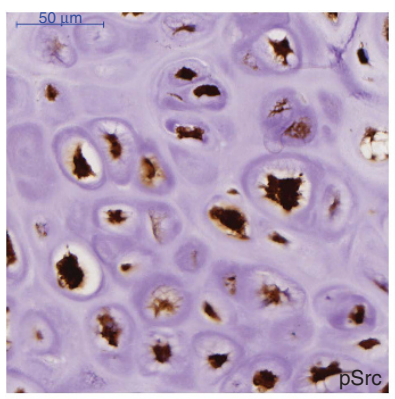

D

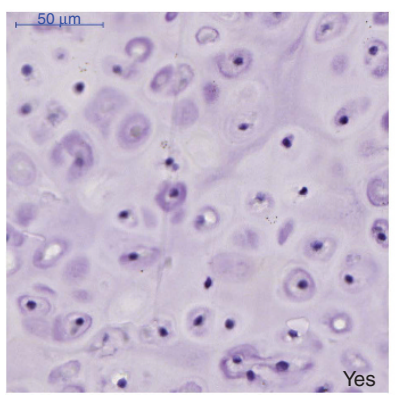

B

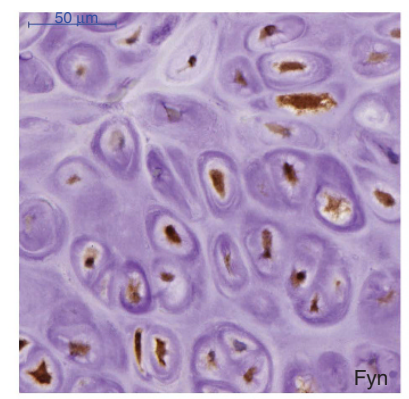

E

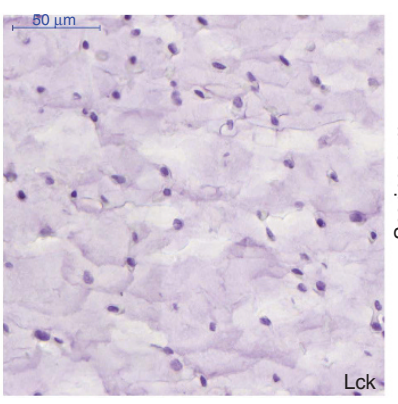

c

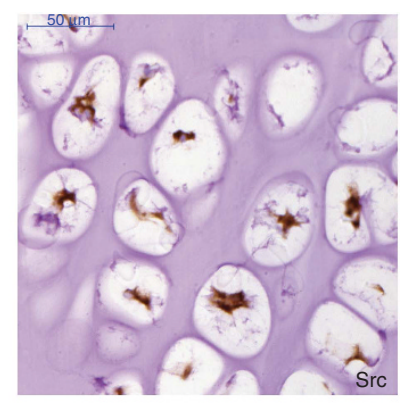

$\mathbf{F}$

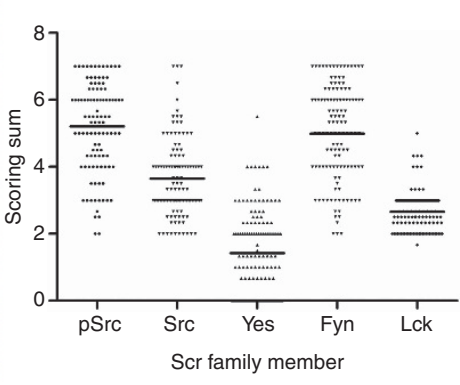

Figure 3. Immunohistochemistry demonstrating expression of Src family members in conventional chondrosarcoma tissue. (A) High pSrc expression in grade I chondrosarcoma. (B) High-intensity nuclear Fyn expression in grade I chondrosarcoma. (C) High-intensity cytoplasmic and nuclear Src expression in grade I chondrosarcoma. (D) Absence of Yes expression in grade II chondrosarcoma. (E) Absence of Lck in grade II chondrosarcoma. Scale bars, $50 \mu \mathrm{m}$. (F) Scatterplot showing distribution of staining scores among chondrosarcoma tissue samples. 
Figure $3 \mathrm{~A}$ and $\mathrm{F})$. Of the four Src family members, we found Fyn (76.1\% high expression, 89 out of 117) and Src (46.6\% high expression, 48 out of 103) to be most abundantly expressed in chondrosarcoma (Table 3, Figure 3B, C and F). In contrast, high expression of Yes and Lck was observed in only $5 \%$ of all chondrosarcoma cases ( 6 out of 116 and 6 out of 120, respectively) (Table 3, Figure 3D-F). During the staining procedures, some cores were lost due to inherent structural instability of the tissue. A significant increase in Src expression was seen between grade I and grade II peripheral CS $(P=0.005$, Pearson chi-squared test). Though not significant, Src expression in tumours was found to be inversely correlated with overall survival $(P=0.3$, log rank). Fyn expression was found to significantly increase with increasing histological grade in both peripheral chondrosarcoma $(P=0.05$ Pearson chi-squared test) and central chondrosarcoma $(P=0.000$, Pearson chi-squared test). No significant correlations to metastasis were found. Using western blot, we confirmed expression of Fyn in all cell lines, with low expression in L835 (Figure 2A).

\section{DISCUSSION}

Chondrosarcomas are resistant to conventional chemotherapy. Despite ongoing research, there is still nothing to offer patients with unresectable or metastatic disease and the need for new, targeted therapies is high. We here explored the effects of increased $\mathrm{PI} 3 \mathrm{~K} / \mathrm{AKT} / \mathrm{GSK} 3 \beta$ and Src signalling on chondrosarcoma chemoresistance and cell migration using enzastaurin and dasatinib, respectively. We show that dasatinib is more effective in overcoming chondrosarcoma chemoresistance than enzastaurin, and acts synergistically with doxorubicin to inhibit cell viability and induce apoptosis. Most importantly, we show that in cell lines with TP53 mutations, the combination of tyrosine kinase inhibitors with doxorubicin is more beneficial than in wild-type TP53 cell lines.

Chondrosarcoma is a heterogeneous disease, and this heterogeneity is represented in the cell lines. Recently, IDH1 and IDH2 mutations were found in chondrosarcoma (Amary et al, 2011), and we published that these mutations are retained in chondrosarcoma cell lines (Pansuriya et al, 2011; van Oosterwijk et al, 2012a). Of the two cell lines that were non-responsive to combination treatment of doxorubicin with dasatinib, one central chondrosarcoma cell line (L835) carried an IDH1 mutation, whereas the other (dedifferentiated chondrosarcoma cell line (L3252)) was wild type for IDH. Thus, no correlation between IDH mutation status and response to dasatinib monotreatment or combination treatment with doxorubicin was observed. More likely, the lack of sensitivity to dasatinib in the L835 cell line is caused by the low pSrc activity in this cell line.

Src inhibition with dasatinib resulted in successful sensitisation for doxorubicin treatment, especially in TP53 mutant chondrosarcoma cell lines. Approximately $30 \%$ of chondrosarcomas carry TP53 mutations, and these mutations are found especially in highgrade chondrosarcomas (Oshiro et al, 1998; Terek et al, 1998). Three of the eight cell lines carry a TP53 mutation (SW1353, JJ012 and NDCS-1), and these cell lines also showed a better response to combination treatment with low combination indices when compared with TP53 wild-type cell lines. This is an interesting result as mutant TP53 is described to actively inhibit apoptosis through activation of p21 (Donzelli et al, 2012) or to confer chemoresistance through engaging in oncogenic transcription complexes (Huang et al, 2012). Previously, dasatinib was found to interfere with the p53 transcriptional activity induced by the MDM2 inhibitor nutlin-3 (Zauli et al, 2011). We show that dasatinib does not affect p53 nor p21 protein expression in chondrosarcoma cells. Dasatinib as a single agent proved ineffective in chondrosarcoma patients (Schuetze et al, 2010). However, recent clinical studies with dasatinib in other malignancies have shown its efficacy not only irrespective of TP53 status as a single agent (Bosco et al, 2012) but also to overcome TP53 mutation status-related chemoresistance (Amrein et al, 2008). The results of these clinical studies in combination with the data we show here strongly suggest clinical evaluation of the efficacy of dasatinib in combination with doxorubicin in chondrosarcoma patients harbouring TP53 mutations.

As we demonstrate Src signalling to have a role in chemoresistance, we further explored the expression of the different Src family kinases (SFKs) in human chondrosarcoma tissues. Fyn was most widely expressed (89 out of 117) and was found to increase with increasing histological grade, suggesting a role in chondrosarcoma progression. Fyn is reported to be upregulated in multiple cancers, and to be associated with malignant progression and metastasis formation (Posadas et al, 2009; Chen et al, 2010; Saito et al, 2010). We confirmed that indeed the Src pathway is important in chondrosarcoma cell motility, as dasatinib completely inhibited migratory capacity of all chondrosarcoma cell lines even at low dose.

Clinical trials with dasatinib have shown the efficacy and low toxicity of dasatinib in combination with conventional chemotherapeutic agents in solid tumours (Montero et al, 2011). In a phase II study of dasatinib with hyper-CVAD in patients with Philadelphia chromosome-positive lymphoblastic leukaemia, long-term remission was achieved in newly diagnosed patients (Ravandi et al, 2010), and in a phase I-II study of dasatinib with doxetaxel in castration-resistant prostate cancer, disappearance of bone lesions was obtained (Araujo et al, 2012). The results obtained with dasatinib in combination with chemotherapy strongly encourage the exploration of dasatinib in combination with doxorubicin in patients with chondrosarcoma.

Both the PI3K/AKT/GSK3 $\beta$ and Src kinase pathways are activated by RTKs (Goode et al, 1992; Wheeler et al, 2009), and have diverse roles in promoting growth, survival and metastasis (Aligayer et al, 2002; Wheeler et al, 2009; Yang et al, 2010; McNamara and Degterev, 2011; Saini et al, 2011). We show here that constitutive activation of AKT due to mutations does not have a role in chondrosarcoma, and further research should elucidate which RTK is responsible for the high AKT, GSK3 $\beta$ and Src phosphorylation (Schrage et al, 2009). A possible candidate is IGF-1, which can activate the PI3K/AKT and Src pathway through the RTK IGF-1R (Grimberg, 2003), and has been shown to induce PI3K/AKT signalling and migration in chondrosarcoma cell lines (Wu et al, 2011). Src family kinases can induce phosphorylation of the RTK domains of IGF-1 as well as the PDGF receptors through SHP-2 leading to receptor internalisation. This increases binding efficacy with PI3K, leading to increased proliferative capacity of cancer cells (Wu et al, 2001; Carver et al, 2010). Moreover, AKT functions as a gatekeeper of apoptosis through phosphorylation of BAD. AKT-mediated phosphorylation of BAD inhibits its binding capacity to antiapoptotic BCL-2 family members, which will prevent a cell from entering apoptosis (Gilmore et al, 2002; Maddika et al, 2007). We recently published that the antiapoptotic BCL-2 family members also have a role in chondrosarcoma chemoresistance (van Oosterwijk et al, 2012b). Combined with the results of the present study, this is suggestive of a common mechanism. However, more studies are needed to explore whether the activation of the IGF pathway by Src leading to the inhibition of $\mathrm{BH} 3$ proteins and apoptosis through AKT may be involved in chondrosarcoma chemoresistance.

In conclusion, we found that inhibition of the Src pathway was successful in overcoming chemoresistance and inhibited migration. A synergistic response to combination treatment was observed, which was significantly stronger $(P=0.002)$ in cell lines harbouring TP53 mutations. Moreover, as we observed the Src family 
member Fyn to be the most prevalent in chondrosarcoma tissues, we hypothesise Fyn to have a major role in the chemoresistance and malignant progression of chondrosarcoma. These results aid in the understanding of signalling pathways in chondrosarcoma and may lead to the development of effective therapeutic strategies for currently untreatable metastatic chondrosarcoma.

\section{ACKNOWLEDGEMENTS}

We thank Dorien van der Geest and Pauline Wijers-Koster for technical assistance. We also thank Bristol Myers Squibb for providing dasatinib and Eli Lilly for providing enzastaurin. We are grateful to Dr JA Block (Rush University Medical Centre, Chicago, IL, USA), who kindly provided us with the JJ012 cell line, to Professor A Llombart Bosch (University of Valencia, Spain) for the cell line CH2879, M Namba (Okayama University Medical School, Shikata, Japan) for the OUMS27 cell line and Dr T Ariizumi (Niigata University Graduate School of Medical and Dental Sciences, Niigata, Japan) for the cell line NDCS-1. This work was financially supported by Dutch Cancer Society (UL2010-4873: JGvO, JVMGB and BvdW) and Netherlands Organization for Scientific Research (917-67-315: JVMGB). This study was performed in the context of EuroSARC, a collaborative project within the EC's 7th Framework programme under grant agreement 278742 .

\section{CONFLICT OF INTEREST}

The authors declare no conflict of interest.

\section{REFERENCES}

Aeder SE, Martin PM, Soh JW, Hussaini IM (2004) PKC-eta mediates glioblastoma cell proliferation through the Akt and mTOR signaling pathways. Oncogene 23(56): 9062-9069.

Aligayer H, Boyd DD, Heiss MM, Abdalla EK, Curley SA, Gallick GE (2002) Activation of Src kinase in primary colorectal carcinoma: an indicator of poor clinical prognosis. Cancer 94(2): 344-351.

Amary MF, Bacsi K, Maggiani F, Damato S, Halai D, Berisha F, Pollock R, O'Donnell P, Grigoriadis A, Diss T, Eskandarpour M, Presneau N, Hogendoorn PC, Futreal A, Tirabosco R, Flanagan AM (2011) IDH1 and IDH2 mutations are frequent events in central chondrosarcoma and central and periosteal chondromas but not in other mesenchymal tumours. J Pathol 224(3): 334-343.

Amrein L, Hernandez TA, Ferrario C, Johnston J, Gibson SB, Panasci L, Aloyz R (2008) Dasatinib sensitizes primary chronic lymphocytic leukaemia lymphocytes to chlorambucil and fludarabine in vitro. Br J Haematol 143(5): 698-706.

Araujo JC, Mathew P, Armstrong AJ, Braud EL, Posadas E, Lonberg M, Gallick GE, Trudel GC, Paliwal P, Agrawal S, Logothetis CJ (2012) Dasatinib combined with docetaxel for castration-resistant prostate cancer: results from a phase 1-2 study. Cancer 118(1): 63-71.

Bosco R, Rabusin M, Voltan R, Celeghini C, Corallini F, Capitani S, Secchiero P (2012) Anti-leukemic activity of dasatinib in both p53(wild-type) and p53(mutated) B malignant cells. Invest New Drugs 30(1): 417-422.

Bovée JVMG, Hogendoorn PCW, Wunder JS, Alman BA (2010) Cartilage tumours and bone development: molecular pathology and possible therapeutic targets. Nat Rev Cancer 10(7): 481-488.

Bovée JVMG, Van den Broek LJCM, Cleton-Jansen AM, Hogendoorn PCW (2000) Up-regulation of PTHrP and Bcl-2 expression characterizes the progression of osteochondroma towards peripheral chondrosarcoma and is a late event in central chondrosarcoma. Lab Invest 80: 1925-1933.

Carpten JD, Faber AL, Horn C, Donoho GP, Briggs SL, Robbins CM, Hostetter G, Boguslawski S, Moses TY, Savage S, Uhlik M, Lin A, Du J, Qian YW, Zeckner DJ, Tucker-Kellogg G, Touchman J, Patel K, Mousses S, Bittner M, Schevitz R, Lai MH, Blanchard KL, Thomas JE (2007) A transforming mutation in the pleckstrin homology domain of AKT1 in cancer. Nature 448(7152): 439-444.

Carver KC, Piazza TM, Schuler LA (2010) Prolactin enhances insulin-like growth factor I receptor phosphorylation by decreasing its association with the tyrosine phosphatase SHP-2 in MCF-7 breast cancer cells. J Biol Chem 285(11): 8003-8012.

Chen ZY, Cai L, Bie P, Wang SG, Jiang Y, Dong JH, Li XW (2010) Roles of Fyn in pancreatic cancer metastasis. J Gastroenterol Hepatol 25(2): 293-301.

Chou TC, Talalay P (1984) Quantitative analysis of dose-effect relationships: the combined effects of multiple drugs or enzyme inhibitors. Adv Enzyme Regul 22: 27-55.

Cleton-Jansen AM, van Beerendonk HM, Baelde HJ, Bovée JVMG, Karperien M, Hogendoorn PCW (2005) Estrogen signaling is active in cartilaginous tumors: implications for antiestrogen therapy as treatment option of metastasized or irresectable chondrosarcoma. Clin Cancer Res 11(22): 8028-8035.

David E, Blanchard F, Heymann MF, De PG, Gouin F, Redini F, Heymann D (2011) The Bone niche of chondrosarcoma: a sanctuary for drug resistance, tumour growth and also a source of new therapeutic targets. Sarcoma 2011: 932451.

Donzelli S, Fontemaggi G, Fazi F, Di AS, Padula F, Biagioni F, Muti P, Strano S, Blandino G (2012) MicroRNA-128-2 targets the transcriptional repressor E2F5 enhancing mutant p53 gain of function. Cell Death Differ 19(6): 1038-1048.

Evans HL, Ayala AG, Romsdahl MM (1977) Prognostic factors in chondrosarcoma of bone. A clinicopathologic analysis with emphasis on histologic grading. Cancer 40: 818-831.

Fang X, Yu S, Tanyi JL, Lu Y, Woodgett JR, Mills GB (2002) Convergence of multiple signaling cascades at glycogen synthase kinase 3: Edg receptormediated phosphorylation and inactivation by lysophosphatidic acid through a protein kinase C-dependent intracellular pathway. Mol Cell Biol 22(7): 2099-2110.

Faul MM, Gillig JR, Jirousek MR, Ballas LM, Schotten T, Kahl A, Mohr M (2003) Acyclic N-(azacycloalkyl)bisindolylmaleimides: isozyme selective inhibitors of PKCbeta. Bioorg Med Chem Lett 13(11): 1857-1859.

Fizazi K (2007) The role of Src in prostate cancer. Ann Oncol 18(11): $1765-1773$.

Gelderblom H, Hogendoorn PCW, Dijkstra SD, van Rijswijk CS, Krol AD, Taminiau AHM, Bovee JVMG (2008) The clinical approach towards chondrosarcoma. Oncologist 13(3): 320-329.

Gelman IH (2011) Src-family tyrosine kinases as therapeutic targets in advanced cancer. Front Biosci (Elite Ed) 3: 801-807.

Gil-Benso R, Lopez-Gines C, Lopez-Guerrero JA, Carda C, Callaghan RC, Navarro S, Ferrer J, Pellin A, Llombart-Bosch A (2003) Establishment and characterization of a continuous human chondrosarcoma cell line, ch-2879: comparative histologic and genetic studies with its tumor of origin. Lab Invest 83(6): 877-887.

Gilmore AP, Valentijn AJ, Wang P, Ranger AM, Bundred N, O'Hare MJ, Wakeling A, Korsmeyer SJ, Streuli CH (2002) Activation of BAD by therapeutic inhibition of epidermal growth factor receptor and transactivation by insulin-like growth factor receptor. J Biol Chem 277(31): 27643-27650.

Goode N, Hughes K, Woodgett JR, Parker PJ (1992) Differential regulation of glycogen synthase kinase-3 beta by protein kinase C isotypes. J Biol Chem 267(24): 16878-16882.

Graff JR, McNulty AM, Hanna KR, Konicek BW, Lynch RL, Bailey SN, Banks C, Capen A, Goode R, Lewis JE, Sams L, Huss KL, Campbell RM, Iversen PW, Neubauer BL, Brown TJ, Musib L, Geeganage S, Thornton D (2005) The protein kinase Cbeta-selective inhibitor, Enzastaurin (LY317615.HCl), suppresses signaling through the AKT pathway, induces apoptosis, and suppresses growth of human colon cancer and glioblastoma xenografts. Cancer Res 65(16): 7462-7469.

Grimberg A (2003) Mechanisms by which IGF-I may promote cancer. Cancer Biol Ther 2(6): 630-635.

Hameetman L, Kok P, Eilers PHC, Cleton-Jansen AM, Hogendoorn PCW, Bovée JVMG (2005) The use of Bcl-2 and PTHLH immunohistochemistry in the diagnosis of peripheral chondrosarcoma in a clinicopathological setting. Virchows Arch 446: 430-437.

Hogendoorn PCW, Bovée JVMG, Nielsen GP (2013) Chondrosarcoma (grades I-III), including primary and secondary variants and periosteal chondrosarcoma. In World Health Classification of Tumours. Pathology and Genetics of Tumours of Soft Tissue and Bone, Fletcher CDM, Bridge JA, Hogendoorn PCW et al. (eds), pp 264-268. 
Huang Y, Jeong JS, Okamura J, Sook-Kim M, Zhu H, Guerrero-Preston R, Ratovitski EA (2012) Global tumor protein p53/p63 interactome: making a case for cisplatin chemoresistance. Cell Cycle 11(12): 2367-2379.

Johnson D, Agochiya M, Samejima K, Earnshaw W, Frame M, Wyke J (2000) Regulation of both apoptosis and cell survival by the v-Src oncoprotein. Cell Death Differ 7(8): 685-696.

Kawakami Y, Nishimoto H, Kitaura J, Maeda-Yamamoto M, Kato RM, Littman DR, Leitges M, Rawlings DJ, Kawakami T (2004) Protein kinase C betaII regulates Akt phosphorylation on Ser-473 in a cell type- and stimulus-specific fashion. J Biol Chem 279(46): 47720-47725.

Kononen J, Bubendorf L, Kallioniemi A, Barlund M, Schraml P, Leighton S, Torhorst J, Mihatsch MJ, Sauter G, Kallioniemi OP (1998) Tissue microarrays for high-throughput molecular profiling of tumor specimens. Nat Med 4(7): 844-847.

Kudo N, Ogose A, Hotta T, Kawashima H, Gu W, Umezu H, Toyama T, Endo N (2007) Establishment of novel human dedifferentiated chondrosarcoma cell line with osteoblastic differentiation. Virchows Arch 451(3): 691-699.

Kunisada T, Miyazaki M, Mihara K, Gao C, Kawai A, Inoue H, Namba M (1998) A new human chondrosarcoma cell line (OUMS-27) that maintains chondrocytic differentiation. Int J Cancer 77(6): 854-859.

Lechler P, Renkawitz T, Campean V, Balakrishnan S, Tingart M, Grifka J, Schaumburger J (2011) The antiapoptotic gene survivin is highly expressed in human chondrosarcoma and promotes drug resistance in chondrosarcoma cells in vitro. BMC Cancer 11: 120.

Lombardo LJ, Lee FY, Chen P, Norris D, Barrish JC, Behnia K, Castaneda S, Cornelius LA, Das J, Doweyko AM, Fairchild C, Hunt JT, Inigo I, Johnston K, Kamath A, Kan D, Klei H, Marathe P, Pang S, Peterson R, Pitt S, Schieven GL, Schmidt RJ, Tokarski J, Wen ML, Wityak J, Borzilleri RM (2004) Discovery of N-(2-chloro-6-methyl- phenyl)-2(6-(4-(2-hydroxyethyl)-piperazin-1-yl)-2-methylpyrimidin-4ylamino)thiazole-5-carboxamide (BMS-354825), a dual Src/Abl kinase inhibitor with potent antitumor activity in preclinical assays. J Med Chem 47(27): 6658-6661.

Maddika S, Ande SR, Panigrahi S, Paranjothy T, Weglarczyk K, Zuse A, Eshraghi M, Manda KD, Wiechec E, Los M (2007) Cell survival, cell death and cell cycle pathways are interconnected: implications for cancer therapy. Drug Resist Updat 10(1-2): 13-29.

Mahajan K, Mahajan NP (2012) PI3K-independent AKT activation in cancers: a treasure trove for novel therapeutics. J Cell Physiol 227(9): 3178-3184.

McNamara CR, Degterev A (2011) Small-molecule inhibitors of the PI3K signaling network. Future Med Chem 3(5): 549-565.

Montero JC, Seoane S, Ocana A, Pandiella A (2011) Inhibition of SRC family kinases and receptor tyrosine kinases by dasatinib: possible combinations in solid tumors. Clin Cancer Res 17(17): 5546-5552.

Oshiro Y, Chaturvedi V, Hayden D, Nazeer T, Johnson M, Johnston DA, Ordonez NG, Ayala AG, Czerniak B (1998) Altered p53 is associated with aggressive behavior in chondrosarcoma; a long term follow-up study. Cancer 83: 2324-2334.

Pansuriya TC, van ER, d'Adamo P, van Ruler MA, Kuijjer ML, Oosting J, Cleton-Jansen AM, van Oosterwijk JG, Verbeke SL, Meijer D, van WT, Nord KH, Sangiorgi L, Toker B, Liegl-Atzwanger B, San-Julian M, Sciot R, Limaye N, Kindblom LG, Daugaard S, Godfraind C, Boon LM, Vikkula M, Kurek KC, Szuhai K, French PJ, Bovée JVMG (2011) Somatic mosaic IDH1 and IDH2 mutations are associated with enchondroma and spindle cell hemangioma in Ollier disease and Maffucci syndrome. Nat Genet 43(12): 1256-1261.

Posadas EM, Al-Ahmadie H, Robinson VL, Jagadeeswaran R, Otto K, Kasza KE, Tretiakov M, Siddiqui J, Pienta KJ, Stadler WM, Rinker-Schaeffer C, Salgia R (2009) FYN is overexpressed in human prostate cancer. BJU Int 103(2): $171-177$.

Puigvert JC, de Bont H, van de Water B, Danen EH (2010) High-throughput live cell imaging of apoptosis. Curr Protoc Cell Biol Chapter 18: Unit-13.

Ravandi F, O'Brien S, Thomas D, Faderl S, Jones D, Garris R, Dara S, Jorgensen J, Kebriaei P, Champlin R, Borthakur G, Burger J, Ferrajoli A, Garcia-Manero G, Wierda W, Cortes J, Kantarjian H (2010) First report of phase 2 study of dasatinib with hyper-CVAD for the frontline treatment of patients with Philadelphia chromosome-positive $(\mathrm{Ph}+)$ acute lymphoblastic leukemia. Blood 116(12): 2070-2077.
Rozeman LB, Hameetman L, Cleton-Jansen AM, Taminiau AHM, Hogendoorn PCW, Bovée JVMG (2005) Absence of IHH and retention of PTHrP signalling in enchondromas and central chondrosarcomas. J Pathol 205(4): 476-482.

Saini S, Arora S, Majid S, Shahryari V, Chen Y, Deng G, Yamamura S Ueno K, Dahiya R (2011) Curcumin modulates microRNA-203-mediated regulation of the Src-Akt axis in bladder cancer. Cancer Prev Res (Phila) 410: 1698-1709.

Saito YD, Jensen AR, Salgia R, Posadas EM (2010) Fyn: a novel molecular target in cancer. Cancer 116(7): 1629-1637.

Schrage YM, Briaire-de Bruijn IH, de Miranda NFCC, van Oosterwijk JG, Taminiau AHM, van Wezel T, Hogendoorn PCW, Bovée JVMG (2009) Kinome profiling of chondrosarcoma reveals Src-pathway activity and dasatinib as option for treatment. Cancer Res 69(15): 6216-6222.

Schuetze SM, Wathen JK, Choy E, Ganjoo K, Chow W, Staddon A, Samuels B, Tawbi H, Patel S, Demetri G, Baker LH (2010) SARC009, A phase II study of dasatinib: results in alveolar soft part sarcoma, chondrosarcoma, chordoma, epithelioid sarcoma or solitary fibrous tumor. CTOS 16th Annual Meeting, Paris, France.

Scully SP, Berend KR, Toth A, Qi WN, Qi Z, Block JA (2000) Marshall Urist Award. Interstitial collagenase gene expression correlates with in vitro invasion in human chondrosarcoma. Clin Orthop Relat Res 376: 291-303.

Shrivastav S, Bonar RA, Stone KR, Paulson DF (1980) An Invitro Assay Procedure to Test Chemotherapeutic Drugs on Cells from Human Solid Tumors. Cancer Res 40(12): 4438-4442.

Soderstrom M, Palokangas T, Vahlberg T, Bohling T, Aro H, Carpen O (2010) Expression of ezrin, Bcl-2, and Ki-67 in chondrosarcomas. APMIS 118(10): 769-776.

Staals EL, Bacchini P, Bertoni F (2006) Dedifferentiated central chondrosarcoma. Cancer 106(12): 2682-2691.

Terek RM, Healey JH, Garin-Chesa P, Mak S, Huvos A, Albino AP (1998) p53 mutations in chondrosarcoma. Diagn Mol Pathol 7(1): 51-56.

van Oosterwijk JG, de Jong D, van Ruler MA, Hogendoorn PC, Dijkstra PS, van Rijswijk CS, Machado IS, Llombart-Bosch A, Szuhai K, Bovée JVMG (2012a) Three new chondrosarcoma cell lines: one grade III conventional central chondrosarcoma and two dedifferentiated chondrosarcomas of bone. BMC Cancer 12: 375 .

van Oosterwijk JG, Herpers B, Meijer D, Briaire-de Bruijn IH, Cleton-Jansen AM, Gelderblom H, van de Water B, Bovée JVMG (2012b) Restoration of chemosensitivity for doxorubicin and cisplatin in chondrosarcoma in vitro: BCL-2 family members cause chemoresistance. Ann Oncol 23(6): $1617-1626$.

Verbeek BS, Vroom TM, Adriaansen-Slot SS, Ottenhoff-Kalff AE, Geertzema JG, Hennipman A, Rijksen G (1996) c-Src protein expression is increased in human breast cancer. An immunohistochemical and biochemical analysis. J Pathol 180(4): 383-388.

Wheeler DL, Iida M, Dunn EF (2009) The role of Src in solid tumors. Oncologist 14(7): 667-678.

Wu CJ, O'Rourke DM, Feng GS, Johnson GR, Wang Q, Greene MI (2001) The tyrosine phosphatase SHP-2 is required for mediating phosphatidylinositol 3-kinase/Akt activation by growth factors. Oncogene 20(42): 6018-6025.

Wu CM, Li TM, Hsu SF, Su YC, Kao ST, Fong YC, Tang CH (2011) IGF-I enhances alpha5betal integrin expression and cell motility in human chondrosarcoma cells. J Cell Physiol 226(12): 3270-3277.

Yang J, Takahashi Y, Cheng E, Liu J, Terranova PF, Zhao B, Thrasher JB, Wang HG, Li B. (2010) GSK-3beta promotes cell survival by modulating Bif-1-dependent autophagy and cell death. J Cell Sci 123(Pt 6): 861-870.

Zauli G, Voltan R, Bosco R, Melloni E, Marmiroli S, Rigolin GM, Cuneo A, Secchiero P (2011) Dasatinib plus Nutlin-3 shows synergistic antileukemic activity in both p53 wild-type and p53 mutated B chronic lymphocytic leukemias by inhibiting the Akt pathway. Clin Cancer Res 17(4): $762-770$.

This work is published under the standard license to publish agreement. After 12 months the work will become freely available and the license terms will switch to a Creative Commons AttributionNonCommercial-Share Alike 3.0 Unported License.

\section{Supplementary Information accompanies this paper on British Journal of Cancer website (http://www.nature.com/bjc)}

